Why pay attention to the artist?

\section{Why pay attention to the artist?}

\section{R J Macnaughton, H M Evans}

\section{The perspective of the artist within medical humanities is part of the focus for this year's Association for Medical Humanities conference}

A major part of the focus for this year's Association for Medical Humanities conference in Truro (10-12 July) will be to examine the perspective of the artist within medical humanities. In part, this is being raised because it is felt that individual artists can become invisible in our field; it is their work that is displayed, discussed, made example of, often without attribution. One of us recently (and rightly) came under fire from an artist at a seminar for showing a work commissioned for a hospital and not mentioning the artist's name. The problem is that in using the arts for their instrumental value ${ }^{1}$ it is easy to forget their creators. However, what more do we gain by taking the artist's perspective into account? Is it more than just polite regard for the genius at work, which enables us to take our understanding of medicine and healthcare in new and exciting directions?

A distinction has to be made here between the role of the artist in arts in health and their role in medical humanities; and between our response to the arts and our consideration and response to the humanities. Looking at this second distinction first, it could be rendered very crudely as follows. When we consider a work of art - a painting, sculpture, a poem, a live performance of a play or music - we respond experientially. We are involved in the art-work with a certain immediacy, and our emotions (even passions) are engaged. When we consider a work of the humanities - history, philosophy, literature, anthropology - the response called from us is discursive, reflective and primarily cognitive. This is, of course, a simplistic distinction as it is certainly the case that works of art as well as discourses in the humanities can raise questions for us about the world, our experience of it and our own nature. Nonetheless the immediate appeal of art has a visceral and emotional character. This takes us back to the first distinction above, as it is this ability of the arts to affect our emotions that gives them a therapeutic role. In the arts, therapies, music, painting and dance enable individuals to examine and act out problems that they are unable to express - or even acknowledge - rationally. Of course, art therapists do not usually claim to retain the role of artist while they are working as therapists. In the direct engagement of arts in health, however, the artist retains that identity while undertaking a therapeutic role within a health care context. ${ }^{2}$ That role as artist is fundamental to the role as therapist. Whereas the doctor or nurse have certain skills and knowledge they can offer to the patient, the artist has her viewpoint as artist, which sees creative potential in people and in contexts both for herself and for others. Whilst the doctor may view the patient as a problem to be solved, the artist sees that person as an opportunity for new work. The relationship between the artist/therapist and the patient, therefore, commences in the light of that positive regard, which in itself provokes a warm emotional reaction from the patient. The artist's role is then to get the patient working creatively, which at its most superficial level, is good fun and distracting but, may also lead to greater understanding of the patient's problems or even to the recognition of latent talent. The artist thus gains both as artist and as therapist from this relationship. Additionally there are more practical benefits, and the arts in health context provides another layer of employment possibilities for artists and also increased visibility for their art. Art works displayed in hospitals, for example, can be brought to the notice of many more people than might visit a gallery space in a year. Of course, this is of benefit to artists only if their work is displayed as if it were in a gallery space, and with appropriate attribution.

It is, therefore, fundamental in artsin-health that the artist be present: she is the midwife for the creativity for others, and their labour can then act as inspiration for her own work. Her identity as an artist is crucial to the process not just for what that offers to others but for what it offers artistic endeavour. Turning to medical humanities, how crucial is the presence of the artist here?

To approach this, consider when one might in any context pay attention to the artist - the artist as individual, the person who is the artist. Leaving aside personal connections, then primarily (we take it) one pays attention when trying to understand more about her art, or more particularly the specific products of her art, her art-works: understand more, that is, than is possible from looking at them merely as the result of something impersonal (for instance, simply as part of a genre, part of a society at a particular time, part of a 'movement'). Understanding in this sense involves appreciation and critical consideration, both positive and negative.

Does a medical humanities perspective involve us in critical appreciation? If it does, the circumstances in which this is need to be spelled out. Chief among them is what it is we think we are trying to do when we take on a medical humanities perspective as such. So, what do we suppose we are trying to do?

Let us say that in medical humanities we are trying to understand the human side of medicine', a complicated and untidy idea which includes inter alia: (i) promoting clinical practice that is sensitive to the experiential dimensions of health and illness; (ii) exploring both theoretical and clinical medicine as a 'science of the human'; and, relatedly (iii) examining what technological medicine and its interventions disclose about embodied human nature. We would therefore be interested in art, insofar as such an interest helped directly in one of these three endeavours. We might then ask whether critical consideration of a piece of art helped clinicians prepare for or undertake clinical practice in (i); or whether it might offer imaginative resources (such as organising metaphors) in our thinking about what sciences are and how they work in (ii); or whether it offered imaginative resources for thinking about embodied human nature in (iii).

This is a somewhat eclectic synopsis of medical humanities perspectives, but each of these might gain from critical consideration of any art-works brought to bear on the particular enquiry being undertaken. If an artist's work attempts exploration of and insight into her experience of the human condition, then its value may in part be gauged accordingly: success in that exploration and insight would partly constitute its artistic success, even though the two endeavours must remain ultimately distinguishable. So the success of work of this kind would seem relevant to its value in promoting sensitive clinical 
practice, and to its value in supplying imaginative resources for understanding medicine and indeed human nature. It seems to follow then that understanding and critically considering art can well be part and parcel of a medical humanities perspective.

But it is less clear that this requires us to pay attention to the individuality of the artist as a person, or that paying attention to the artist as such offers anything to the critical consideration of her work. For instance, knowing the artist's personal convictions underlying her work can be of biographical interest, but does it help us gauge the work's value?

Notoriously, does a knowledge of the artist's intentions give us any guide to our own proper response to her work? There are many reasons to think not. Her intentions may be misplaced or unrealistic, since we may reject as mediocre the work that had been meant to be of lasting artistic value and influence; or they may be unworthy, since work may have been produced for propaganda purposes; or they may be irrelevant (such work produced for propaganda purposes may, in the event, transcend its context); or they may be wrongly constraining, since the artist may intend only a single possible interpretation of her work when, by contrast, we might think genuine art invites a complexity of possible interpretations; or - most likely - they may simply be unknowable, as in the case of those dead artists whose intentions were never communicated. (Furthermore, as Cavell wittily argues, there may be a too-lazy alternative to the hard work of asking ourselves how the art-object conveys what it conveys, even when what it conveyed are indeed the intentions of the artist, known, available and relevant. ${ }^{3}$ )
What else is important about the artist, if not her intentions? Presumably, her context and the influences (such as her adopted artistic traditions, pertinent developments of her chosen genres etc.) upon her work. But these influences operate either by guiding her intentions, or by constraining (or making possible) what she produces - that is, by guiding her results. If we are not decisively interested in her intentions for the reasons just given, then we are at most interested in the limiting (though perhaps enabling) effect of the influences on her. To pursue these, it seems that we do need relevant biographical and socio-cultural information. Yet even so, we seem here to be paying attention to the artist as a causal agent rather than as a personality or as an individual 'will' - we attend to her agency rather than to her psychology or personality. And the agency is shown in what the artist produces. So for the essentially discursive endeavours we described above, it is difficult to see why (other than for reasons of homage or celebrity) we should be specially interested in responding to her as an individual rather than to her work.

It might finally be objected by those of a more behaviourist persuasion that it is the agency and actions of the artist which constitute her as an individual, and so an interest in her artistic output is, essentially, an interest in her - or all that an interest in her can properly amount to. But whilst we might concede that people are more than their 'inner lives', we could still plausibly deny that an interest in her artistic output constitutes meaningful attention to the artist as a person. Normally what we mean by being interested in someone for her own sake is being interested in what constitutes her life, which is to say the sorts of things that constitutes our own lives or anyone's life - family circumstances, relationships, hopes and plans, and so forth. Now in medical humanities we often have every reason to explore individual lives in this way but because the lives in question are those of patients, carers, or clinicians, and not those of artists as such.

As we have set it out here, the relevance of the person of the artist seems to differentiate between medical humanities and arts in health. To summarise, in arts in health the artist herself acts as the midwife for creative expression - and her presence is still required for that expression to work therapeutically. In medical humanities the work of art may act as the 'midwife' for intellectual exploration and understanding and further expansion of this exploration will develop independently of both the work and its creator. We look forward to the forthcoming conference in Truro as an opportunity to explore whether our view is an incomplete one.

$J$ Med Ethics; Medical Humanities

2005;31:1-2.

doi: 10.1136/jmh.2005.000189

\section{Authors' affiliations}

R J Macnaughton, H M Evans, Centre for Arts and Humanities in Health and

MedicineUniversity of Durham, UK

Correspondence to: Dr Jane Macnaughton, jane.macnaughton@durham.ac.uk

\section{REFERENCES}

1 Pickering $\mathbf{N}$. 'The use of poetry in health care ethics education'. J Med Ethics: Medical Humanities 2000;26(1):31-6.

2 Macnaughton J, White M, Stacy R. 'Researching the benefits of arts in health'. Health Education 2005; (In press).

3 Cavell S. 'A matter of meaning it'. In Must We Mean What We Say? Cambridge: Cambridge University Press, 1976:213-237. 